\title{
LETTERS
}

\section{Is it time to develop AGREE III?}

As recently pointed out by Djulbegovic and colleagues, ${ }^{1,2}$ if we are to improve delivery of health care, there must be an awareness that quality-improvement initiatives that fail to process underlying evidence rigorously and adapt this evidence to the local environment may prove wasteful and even harmful. Maybe, almost 10 years after AGREE II (Appraisal of Guidelines, Research and Evaluation) was launched, this wise statement is applicable to the AGREE II initiative? ${ }^{3}$

AGREE II focuses on quality of guideline development, but it has been shown that methodologic quality is not sufficient to ensure that recommendations are appropriate and accurate. ${ }^{4-12}$ It may be a good starting point for health care professionals to evaluate guideline quality, but then they should also evaluate guideline content before they decide to implement any recommendation in daily practice.

Of the hundreds of methodologic evaluations of guidelines done with the help of the AGREE instrument that have been published so far (some of which have been reviewed in articles referenced here ${ }^{13-15}$ ), only a small minority also evaluated the content of guidelines. We may not be certain that AGREE has been harmful, but if AGREE-II is not improved in the near future, it may end up becoming wasteful.

Maybe it is time to think about AGREE III, taking the proposal of Djulbegovic and colleagues into account?

\section{Joseph Watine PharmD}

Consultant, laboratory medicine, Hôpital de Villefranche-de-Rouergue, France

Cite as: CMAJ 2019 October 28;191: E1189. doi: 10.1503/cmaj.73257

\section{References}

1. Djulbegovic B, Bennett CL, Guyatt G. Failure to place evidence at the centre of quality improvement remains a major barrier for advances in quality improvement. J Eval Clin Pract 2019;25: 369-72.

2. Djulbegovic B, Bennett CL, Guyatt G. A unifying framework for improving health care. J Eval Clin Pract 2019;25:358-62.

3. Brouwers MC, Kho ME, Browman GP, et al.; AGREE Next Steps Consortium. AGREE II: advancing guideline development, reporting and evaluation in health care. CMAJ 2010;182:E839-42.

4. Burgers JS. Guideline quality and guideline content: Are they related? Clin Chem 2006;52:3-4.

5. Watine J, Friedberg B, Nagy E, et al. Conflict between guideline methodologic quality and recommendation validity: a potential problem for practitioners. Clin Chem 2006;52:65-72.

6. Watine JC, Bunting PS. Mass colorectal cancer screening: methodological quality of practice guidelines is not related to their content validity. Clin Biochem 2008;41:459-66.

7. Matthys J, De Meyere M. Quality evidence important for quality guidelines. CMAJ 2010;182:1449-50.

8. Matthys J, De Meyere M, van Driel ML, et al. Differences among international pharyngitis guidelines: not just academic. Ann Fam Med 2007;5:436-43.

9. Nuckols TK, Lim YW, Wynn BO, et al. Rigorous development does not ensure that guidelines are acceptable to a panel of knowledgeable providers. J Gen Intern Med 2008;23:37-44.

10. Eikermann M, Holzmann N, Siering U, et al. Tools for assessing the content of guidelines are needed to enable their effective use - a systematic comparison. BMC Res Notes 2014;7:853.

11. Coates D, Homer C, Wilson A, et al. Induction of labour indications and timing: a systematic analysis of clinical guidelines. Women Birth 2019 July 5 [Epub ahead of print]. doi: 10.1016/j.wombi.2019.06.004.

12. Pallari E, Fox AW, Lewison G. Differential research impact in cancer practice guidelines' evidence base: lessons from ESMO, NICE and SIGN. ESMO Open 2018;3:e000258.

13. Alonso-Coello P, Irfan A, Solà I, et al. The quality of clinical practice guidelines over the last two decades: a systematic review of guideline appraisal studies. Qual Saf Health Care 2010;19:e58.

14. Armstrong JJ, Goldfarb AM, Instrum RS, et al. Improvement evident but still necessary in clinical practice guideline quality: a systematic review. J Clin Epidemiol 2017;81:13-21.

15. Gagliardi AR, Brouwers MC. Do guidelines offer implementation advice to target users? A systematic review of guideline applicability. BMJ Open 2015;5:e007047.

Competing interests: None declared. 